\title{
Factors that Influence the Performance of Terrestrial Digital TV Receivers in São Paulo
}

\author{
Paulo Guedes Esperante, Raquel Cymrot, Cristiano Akamine, Fujio Yamada, Rodrigo Eiji Motoyama, \\ and Fabio Raia
}

\begin{abstract}
This article presents the factors that may degrade the reception of a digital TV signal, through the analysis of a communication channel. Methodologies and factorial experimental results with the communication channel are presented, and the analysis of meteorological factors that influence the reception quality of the ISDB- $T_{B}$ system based on data regarding the quality of the digital signals collected from some TV stations in São Paulo. From the data obtained, statistical techniques were applied, such as planning and analysis of factorial experiments, simple and multiple linear regressions tests for measurement equality in order to determine which factors had greater influence on the degradation of digital TV signal.
\end{abstract}

Index Terms-Digital TV, Meteorology, Statistics.

\section{INTRODUCTION}

A CCESS of digital TV signals by the general population is related in part to the quality of the signal received. A digital TV, with the use of its interactive possibilities, can provide services and information to citizens. With a better understanding of the factors that can influence the reception quality it is possible to better plan the receivers locations, to maximize coverage in the country, leading to the inclusion of this service for more Brazilian citizens.

One of the factors that influence the digital signal reception quality are the noises. The noises are spurious that disturb the transmission channel and signal reception processing and can be classified as external system factors, for example, atmospheric noise, galactic noise, manmade noise or the internal system factors, for example, impulsive noise and thermal noise [1]. These noises are related to various meteorological factors and, therefore, cause disturbances in the transmission channel.

Based on this concept, data was collected simultaneously regarding both digital signal quality and meteorological conditions. By applying statistical methodologies to the

Paulo Guedes Esperante is a researcher at Mackenzie Presbyterian University, São Paulo, Brazil (e-mail: pauloesperante@gmail.com).

Raquel Cymrot is a professor at Mackenzie Presbyterian University, São Paulo, Brazil (e-mail: raquelc@mackenzie.br).

Cristiano Akamine is a professor at Mackenzie Presbyterian University, São Paulo, Brazil (e-mail: cristiano.akamine@mackenzie.br).

Fujio Yamada is a researcher at Mackenzie Presbyterian University, São Paulo, Brazil (e-mail: fujio.yamada@mackenzie.br).

Rodrigo Eiji Motoyama is a researcher at Mackenzie Presbyterian University, São Paulo, Brazil (e-mail: rodrigo.motoyama@gmail.com).

Fabio Raianrim is a researcher at Mackenzie Presbyterian University, São Paulo, Brazil (e-mail: raia@gmail.com). results, it was possible to check the meteorological factor with the greatest influence on the degradation of the digital signal quality in the Integrated Services Digital BroadcastingTerrestrial version $B$ system $\left(\right.$ ISDB- $\mathrm{T}_{\mathrm{B}}$ ).

With the constant evolution of technology and having a predetermined system, further research should be conducted. When the survey includes quantitative data collection, it is necessary that the statistical analysis of the data is performed by a careful choice of the tools used, always testing the validity of the model assumptions necessary for the application of each analysis technique [2].

Among the possible statistical methodologies that may be used, $2^{\mathrm{k}}$ factor sampling stands out, which is very useful in preliminary investigations when it is necessary to determine the main factors and interactions that can influence the result of an experiment. In this case, each factor is presented in two distinct levels as reference [3]. This method is used by scientists and engineers aiming to improve systems, processes, and products based on the results obtained in these experiments.

Another application methodology is multiple regression analysis that aims to model and investigate the relationship between a dependent variable and one or more explanatory variables (regressive) [2].

For the two methods mentioned above it is essential to carry out residual analysis to verify the theoretical assumptions needed for their use were met [2].

\section{ADOPTED PROCEDURE}

In order to relate the digital modulated signal in the ISDB$\mathrm{T}_{\mathrm{B}}$ standard with meteorological data, the meteorological variables analyzed that have the ability to contribute to noise generation in digital TV signal reception were: wind speed $(\mathrm{m} / \mathrm{s})$, wind direction, temperature $\left({ }^{\circ} \mathrm{C}\right)$, Pressure $(\mathrm{hPa})$, and light intensity $\left(\mathrm{W} / \mathrm{m}^{2}\right)$. To assess the quality of the digital signal the signal level and signal-to-noise ratio $(\mathrm{C} / \mathrm{N})$ for receiving data in each channel were observed. These measurements were made in São Paulo, in the Itambé campus of Universidade Presbiteriana Mackenzie, with a meteorological data collection system and a VHF/UHF antenna, connected to a demodulator, installed very close to each other. To evaluate the signal quality some TV stations in São Paulo with digital signal transmission were selected, and data collection was completed within one week for each TV station.

A statistical tool was applied to the collected data in order to check the level of influence of each variable under study. 
In factorial experiments, it is common to use a table of contrasts to simplify calculations for checking existence of the main effects and interactions among the variables. The factorial experimental are also known for delimitation of $\mathrm{L}^{\mathrm{k}}$, where $\mathrm{k}$ stands for the total number of factors in this experiment and $\mathrm{L}$ is the number of levels tested for each factor, assumed equal, as reference [4]. $2^{3}:$

Table I outlines the contrasts for an experiment design for

TABLE I

CONTRAST COEFFICIENTS OF A $2^{3}$ FACTORIAL DESIGN INPUT

\begin{tabular}{cccccccc}
\hline \multirow{2}{*}{ Experiment } & \multicolumn{7}{c}{ Interactions } \\
& A & B & C & AB & AC & BC & ABC \\
\hline 1 & -1 & -1 & -1 & 1 & 1 & 1 & -1 \\
2 & 1 & -1 & -1 & -1 & -1 & 1 & 1 \\
3 & -1 & 1 & -1 & -1 & 1 & -1 & 1 \\
4 & 1 & 1 & -1 & 1 & -1 & -1 & -1 \\
5 & -1 & -1 & 1 & 1 & -1 & -1 & 1 \\
6 & 1 & -1 & 1 & -1 & 1 & -1 & -1 \\
7 & -1 & 1 & 1 & -1 & -1 & 1 & -1 \\
8 & 1 & 1 & 1 & 1 & 1 & 1 & 1 \\
\hline \hline
\end{tabular}

Source - Barros; Scarminio; Bruns (2003, p.111)

All factors begin with the value -1 . The first factor (A) changes the signal every $2^{0}=1$ line. The second factor (B) changes the signal every $2^{1}=2$ lines. The third factor (C) changes the signal every $2^{2}=4$ lines. If it had more factors, the signals would follow these rules successively. In the interaction between the factors, the signal used is related to the multiplication of signals between its columns, in the corresponding lines.

The experimental design should provide the necessary answers, using the lowest possible number of experiments (runs). When economic conditions and time to perform the experiments permit, it is advisable that the design use at least two replicas so that it is possible to estimate the error without confusion. When the use of replicas is not possible, the error will be confused with minimum interactions to the order of three, because they are generally negligible [2].

In factorial experiment $2^{4}$, on the threshold (-1) the variables were at their minimum, those being multipath, impulsive noise, white noise, and signal intensity. In this situation, the signal would not be suffering sufficient inference to cause degradation in the image decoded by the receiver. At level $(+1)$ the signal would be suffering interference (the same commented previously). The $\mathrm{C} / \mathrm{N}$ ratio used was $22 \mathrm{~dB}$, the value adopted being slightly above that recommended by the Agência Brasileira de Normas Técnicas (ABNT), whose signal-to-noise ratio is $19 \mathrm{~dB}$ to determine the parameters of the variables, which can be seen in [5].

In the second experiment of this article, the Kruskal-Wallis test was used to decide whether the samples come from the same or different populations. This non-parametric test is used when the assumptions to perform parametric variance analysis do not exist and only requires that random errors have the same continuous distribution to all levels of the factor in question. In the Kruskal-Wallis test, each observation is replaced by its respective position as reference [6].
The Kruskal-Wallis test uses the H-statistic calculated by the expression (1):

$H=\frac{12}{N(N+1)} \sum_{i=1}^{a} \frac{R_{i}^{2}}{n_{i}}-3(N+1)$

where $\mathrm{N}$ equals the total number of observations, $\mathrm{n}_{\mathrm{i}}$ is the number of factor observations in the level $\mathrm{i}$, and $\mathrm{R}_{\mathrm{i}}$ equals the sum of the posts of factor observations in level $i$. If there is an equal value in posts, an average posts is used and the expression changes to (2):

$H=\frac{1}{S^{2}}\left[\sum_{i=1}^{a} \frac{R_{i}^{2}}{n_{i}}-\frac{N(N+1)^{2}}{4}\right]$

where $S^{2}$ is equal to the posts variance.

Rejecting the equality hypothesis of the average in the various levels of factor if $\mathrm{H}$ is greater than the value of the chisquare with ( $a-1)$ degrees of freedom, if $a=3$ and $n_{i} \geq 6$ for all $i$ or if $a>3$ and $n_{i} \geq 5$ for all $i$ seen in [2].

\section{LABORATORY EXPERIMENTS}

For the study of factors that can influence the internal antenna reception performance, emulations were completed with the following devices: a Rohde \& Schwartz SFUBroadcasting Test System signal source model, a Spirent TAS Signal Simulator 4500 Flex RF Chanel emulator model, a Rohde \& Schwarz RF step attenuator, two Huber + Suhner combiners, a TAS-impulsive noise generator, a Micronetics white noise generator, a demodulator plate developed by Mackenzie, a HP VSB/QAM HP89441-V Spectrum Signal analyzer, and a Huber + Suhner impedance detector ("Ballun").

The emulation for transmitting the digital signal was performed in channel 15 with a frequency of $479 \mathrm{MHz}+1 / 7$ MHz. The transmission parameters used in the tests were: $1 / 6$ guard interval, 64 QAM modulation, and Mode 3, 3/4 FEC (Forward Error Corrector), and time interleaving of 0.2 seconds. Such standards are commonly used in practice by many broadcasters, and these characteristics were the same in both experiments. Emulations were made within a Faraday cage present in the laboratório da TV Digital da Escola de Engenharia Eléctrica da Universidade Presbyterian Mackenzie in order to avoid adjacent channel interference and co-channel of digital TV signals broadcast in São Paulo.

Experiments with a $2^{4}$ factor design were performed, in which the variables were analyzed: signal level (-64.02 $\mathrm{dBm}$ power just below the threshold and $-61.02 \mathrm{dBm}$ just above the threshold), the presence of white noise interference (with $92.78 \mathrm{dBm}$ power just below the threshold and $-90.00 \mathrm{dBm}$ just above the threshold), the presence of impulsive noise interference (with a power of $-88.4 \mathrm{dBm}, 10 \mathrm{~ms}$ periods and window width varying between $1 \mathrm{~ms}$ and $3 \mathrm{~ms}$, respectively below and above the threshold), the presence of multipath (63 $\mu$ s delay with $6 \mathrm{~dB}$ attenuation with respect to the main signal just below the threshold and $3 \mathrm{~dB}$ just above the threshold), with an ISDB- $\mathrm{T}_{\mathrm{B}}$ digital receiver.

Statistical tests were performed with the help of Minitab ${ }^{\circledR}$ statistical software, with a significance level equal to $5 \%$. 


\section{RESULTS}

Two experiments were conducted at the laboratório da TV digital at Universidade Presbyterian Mackenzie. In the first experiment, $2^{4}$ factor, there were three replicas of each treatment with the following factors, multipath, white noise interference, signal strength, and impulsive noise interference. Variables collected were signal level, $\mathrm{C} / \mathrm{N}$ rate, bit error after the convolutional decoder (Layer A), Layer A packet error after the Reed Solomon Decoder (number of erroneous packets in the layer).

Table II presents the descriptive factor levels and interactions that were significant for any of the variables measured. The number of Layer A error packets was not submitted because their values were mostly zero, and not having such adequate data precision. Residual did not show normal distribution.

TABLE II

DESCRIPTIVE LEVELS OF SOME EFFECTS AND INTERACTIONS

\begin{tabular}{lccc}
\hline \hline Term & Signal level & $\mathrm{C} / \mathrm{N}$ & Layer A \\
\hline multipath (A) & 0.002 & 0.000 & 0.000 \\
white noise (B) & 0.400 & 0.000 & 0.000 \\
signal intensity (C) & 0.673 & 0.050 & 0.165 \\
impulse noise (D) & 0.000 & 0.000 & 0.000 \\
$\mathrm{~A}^{*} \mathrm{~B}$ & 0.4000 & 0.000 & 0.000 \\
\hline \hline
\end{tabular}

The researchers decided it would be better to only investigate the multipath factors and impulse noise, because they are the ones who have the greatest influence on the reception quality of the Brazilian digital TV system using four levels of each variable.

To find a limit for each threshold and determine which form of noise is predominant over the signal, another experiment was performed with impulsive noise and multipath factors, but with four levels each. The values used for the impulsive noise level was $-84.4 \mathrm{dBm}$ for a period of $10 \mathrm{~ms}$ and a window width of $3 \mathrm{~ms}$, and the four levels ranged from $-37 \mathrm{dBm}$ to -46 $\mathrm{dBm}$ in $3 \mathrm{dBm}$ increments. The reception threshold in the presence of multipath was completed by adjusting the main signal to $-54 \mathrm{dBm}$ in the presence of a delayed echo signal of $62.2 \mu$ s with respect to the main signal. In this test, the echo level was attenuated from 0 to $6 \mathrm{~dB}$ with a variation of $2 \mathrm{~dB}$ in relation to the principal signal level. The initial value of the $\mathrm{C} / \mathrm{N}$ ratio established for this test was $23 \mathrm{~dB}$.

Only the $\mathrm{C} / \mathrm{N}$ and bit error variables after the convolutional decoder (Layer A) could be evaluated, once the variable signal level is kept constant for each multipath level, the number of packet errors in Layer A were not precisely adequate. For the $\mathrm{C} / \mathrm{N}$ variable, the residual did not show a normal distribution $(\mathrm{P}<0.005)$, nor equal variances $(\mathrm{P}=0.011$ for the Levene test). The variable bit error after the convolutional decoder (Layer A) had two main effects, as well as its significant interaction, all with $\mathrm{P}=0.000$. Its residual had a normal distribution ( $\mathrm{P}=0.107)$, but the variances equality assumption was not observed ( $\mathrm{P}=0.029$ for the Bartlett test). As can be seen in [7], test $\mathrm{F}$ is robust.

Fig. 1 presents bit error residual after the convolutional decoder (Layer A).

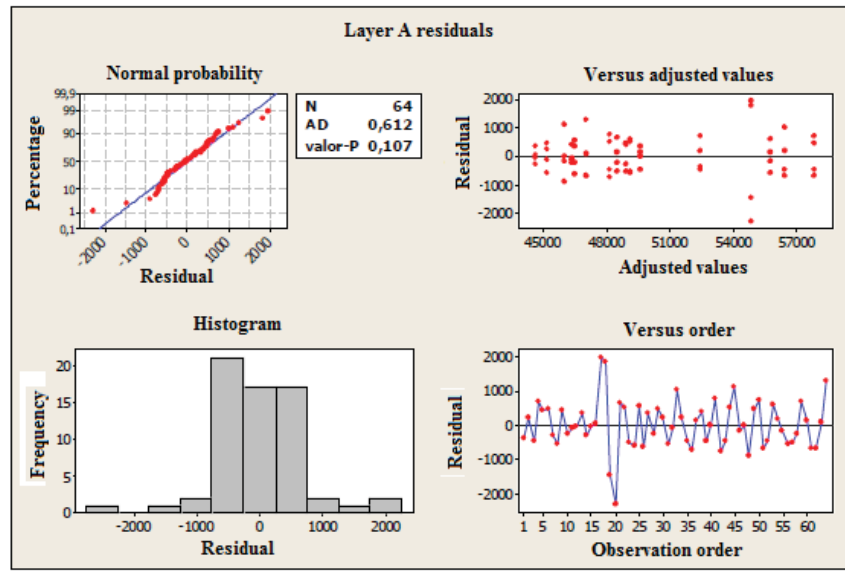

Fig. 1. Residual plots for the variable Layer A

It was decided to perform only a descriptive analysis by analyzing the charts of individual values for the variables signal level, $\mathrm{C} / \mathrm{N}$, and bit error after the convolutional decoder (Layer A), and Layer A packages errors after the Reed Solomon decoder (number of error packets in Layer A) as shown in Figs. 2, 3, 4, and 5.

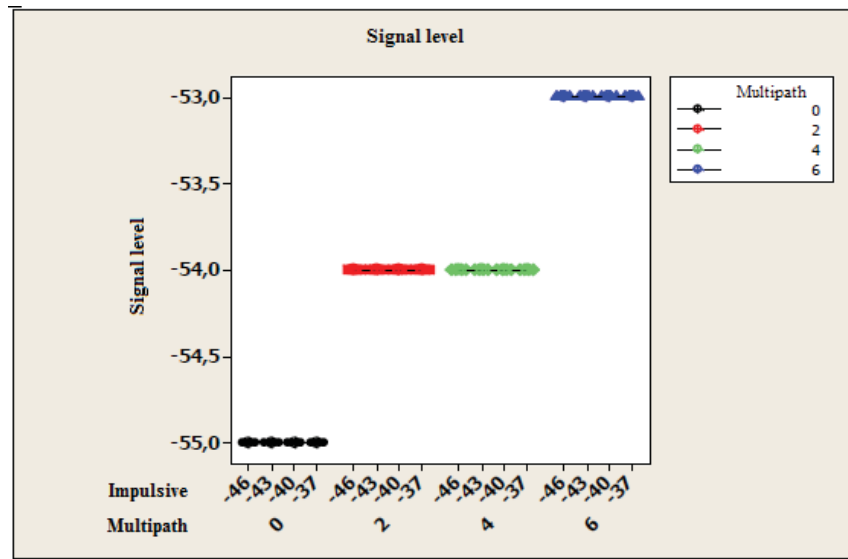

Fig. 2. Individual values for signal level, varying multipath and impulsive noise

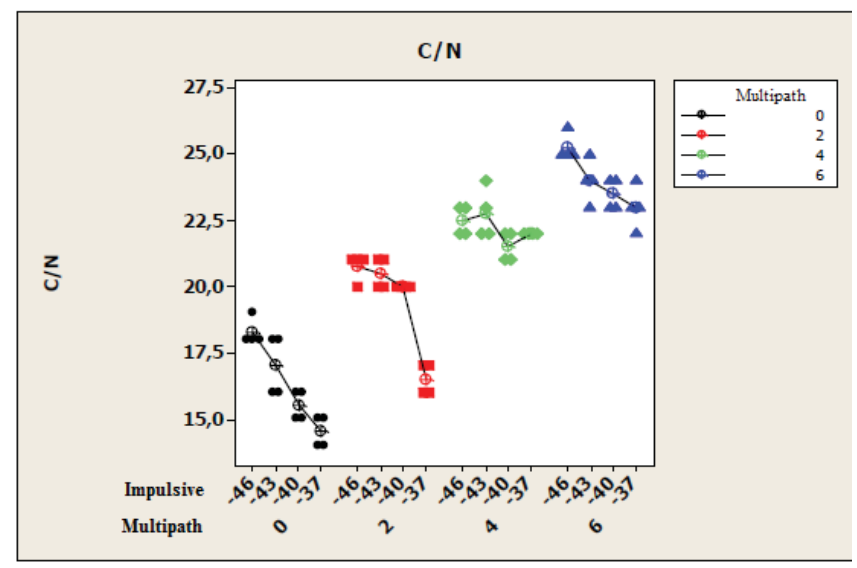

Fig. 3. Individual values for $\mathrm{C} / \mathrm{N}$, varying multipath impulse noise 


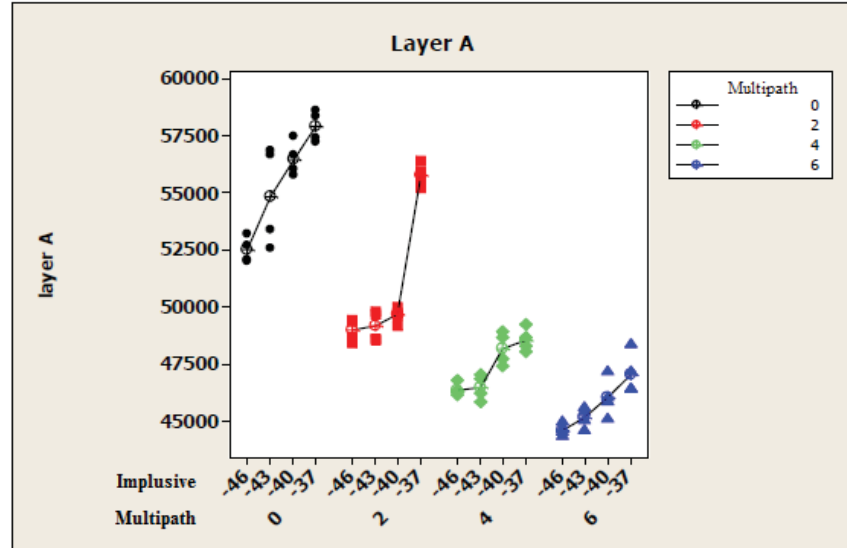

Fig. 4. Individual values for Layer A, varying multipath and impulse noise

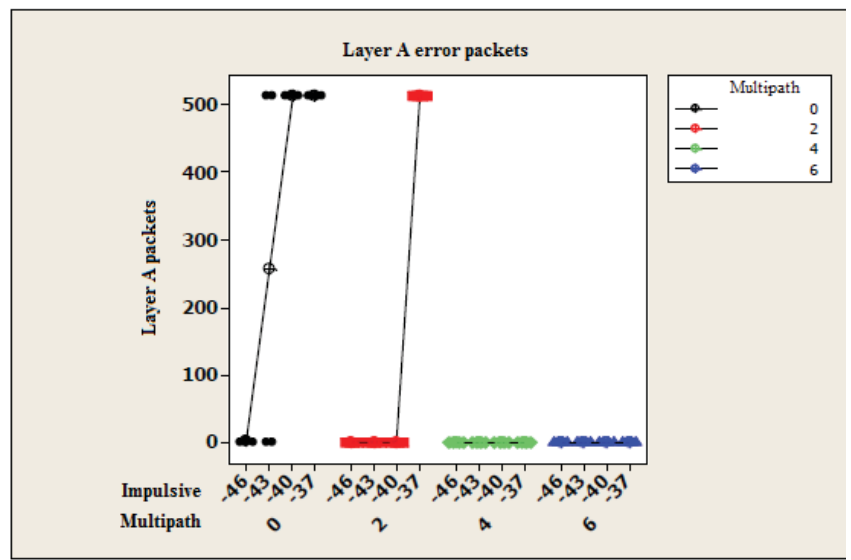

Fig. 5. Individual values for the number of the error packets in Layer A, varying multipath and impulsive noise.

The results show that for the signal level, when enhancing the echo power of the multipath, the signal was less degraded. In this case, the variation in the intensity of impulsive noise did not influence the results. The signal level remained constant for the same multipath even though the impulsive noise varied. For the $\mathrm{C} / \mathrm{N}$ rate, when enhancing the echo power of the multipath, the signal was less degraded, but by increasing the intensity of the impulsive noise the signal suffered more degradation. When a signal is less degraded fewer errors occurred (Layer A), as the signal level of the echo is increased and by the fact that the echo signal boosts the received signal the number of errors decreases. The opposite occurs by increasing the intensity of impulsive noise. For multipath $4 \mathrm{~dB}$ and $6 \mathrm{~dB}$ (attenuation), there were no error packets in Layer A after the Reed Solomon decoder.

In the second part of the research, based on data collected by the external antenna, the transmissions are made by stations A, B, C, D, E, F, G, and H are divided into three clusters. Fig. 6 shows the arrangement of the clusters:

Mean equality tests were carried out for the $\mathrm{C} / \mathrm{N}$ and the signal level, using the non-parametric Kruskal-Wallis test, in both cases, the equality assumptions for all measurements were rejected $(\mathrm{P}=0.000)$.

In the $\mathrm{C} / \mathrm{N}$ analysis, stations with the highest average were those of cluster 2 with two stations that obtained the highest $\mathrm{C} / \mathrm{N}$, followed by a station in cluster 1 and a station in cluster
3. Stations with a lower level response are three stations in cluster 1 and a station in cluster 3 . One possible reason for cluster 2 obtaining the highest average is the fact that these are located closer to the Mackenzie receiver. In turn, the lowest average may have occurred due to the signal power transmitted by such stations.

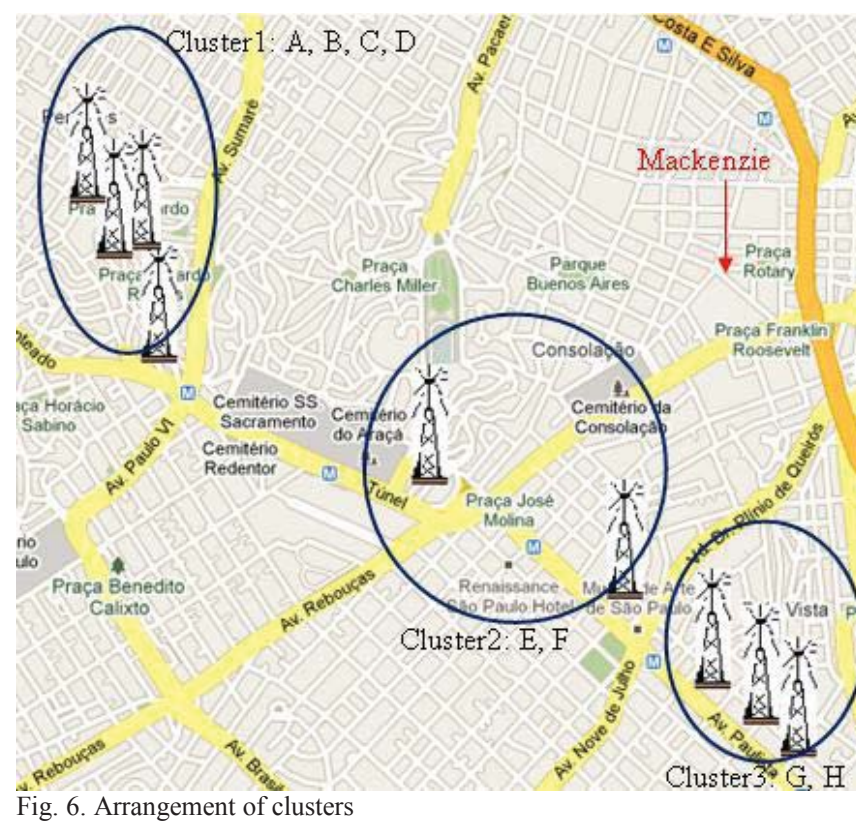

Simple and multiple regressions were performed for $\mathrm{C} / \mathrm{N}$ and the signal level using possible regressive variables like temperature, wind speed, wind direction, pressure, and intensity of light. The humidity variable, though presumably important, cannot be used because of strange values presented in its measurements.

In all possible regressions, the residuals did not adhere to the Normal distribution, nor was there independence between them. Due to the model assumptions not being satisfied their use was not possible. This article merely studied the linear correlations between the variables temperature, wind speed, wind direction, pressure and intensity of light, with a $\mathrm{C} / \mathrm{N}$ and signal level variable for each station, presented in Tables III and IV.

TABLE III

METEOROLOGICAL VARIABLES, LINEAR CORRELATION COEFFICIENT AND PVALUE FOR C/N

\begin{tabular}{cccc}
\hline \hline Issuer & Variables & Correlation & P-value \\
\hline H & Temperature & -0.269 & 0.000 \\
G & Temperature & -0.333 & 0.000 \\
H & Wind speed & -0.292 & 0.000 \\
F & Wind speed & 0.268 & 0.001 \\
G & Wind speed & -0.29 & 0.000 \\
F & Wind direction & 0.486 & 0.000 \\
G & Wind direction & -0.154 & 0.047 \\
E & Pressure & 0.328 & 0.000 \\
G & Light intensity & -0.171 & 0.027 \\
\hline \hline
\end{tabular}


Stations $\mathrm{G}$ and $\mathrm{H}$ showed decreasing linear relation between $\mathrm{C} / \mathrm{N}$ and the temperature, which can be explained by the thermal noise of the receiver. With increased temperature, the $\mathrm{C} / \mathrm{N}$ ratio decreases. Another possible reason is that stations $\mathrm{G}$ and $\mathrm{H}$ are subject to the adjacent channel effect, since both are close in terms of frequency range. Furthermore, the physical location is next to one another, are thereby subject to the same temperature variation. Possibly the light intensity variable at station $\mathrm{G}$ had a negative correlation with the $\mathrm{C} / \mathrm{N}$, as a warmer day tends to have higher brightness.

TABLE IV

Meteorological VARIABLES, LINEAR CORRELATION COEFFICIENT AND PVALUE FOR THE SIGNAL LEVEL

\begin{tabular}{cccc}
\hline \hline Issuer & Variables & Correlation & P-value \\
\hline F & Temperature & -0.570 & 0.000 \\
B & Temperature & 0.239 & 0.002 \\
C & Temperature & 0.400 & 0.000 \\
E & Wind speed & -0.213 & 0.009 \\
F & Wind speed & 0.241 & 0.003 \\
G & Wind speed & -0.196 & 0.011 \\
C & Wind speed & 0.153 & 0.033 \\
F & Wind direction & 0.246 & 0.002 \\
H & Pressure & -0.346 & 0.000 \\
E & Pressure & 0.352 & 0.000 \\
F & Pressure & 0.220 & 0.006 \\
B & Pressure & -0.375 & 0.000 \\
C & Pressure & -0.153 & 0.033 \\
F & Light intensity & -0.557 & 0.000 \\
B & Light intensity & 0.184 & 0.017 \\
C & Light intensity & 0.192 & 0.007 \\
\hline \hline
\end{tabular}

At the same time, it was found that the wind speed and wind direction are related in the same way with $\mathrm{C} / \mathrm{N}$, having a positive or negative correlation, depending on the station. One possible reason for this situation is the balance of the receiving antenna, which changes the directivity beam of the antenna (the receiving antenna is directive). The correlation was, therefore, positive for certain other stations, and in fact negative for other due to the distance and location of each transmitter relative to the receiver antenna having the wind speed and wind direction favoring or hampering the transmission.

Another possible explanation could be the fact that the humidity may have influenced this result since the humidity in some situations varies the azimuth of the horizontal plane favoring or hampering the signal level. However, the data concerning the humidity had to be discarded, being a suggestion for the development of another study where this variable can be measured more reliably.

The pressure variable appeared with linear correlation significantly different from zero, possibly being indirectly related to humidity and as the humidity factor cannot be considered due to problems found in data collection, in addition the pressure variable cannot be considered as a precise variable. There are cases where the pressure interferes with the transmission, but its occurrence would be in frequency waves above $1 \mathrm{GHz}$, which is not the case for standard Brazilian digital TV broadcasts.
Stations F, B, and C were significantly different from a zero correlation between the signal level and temperature, which may again be explained by the thermal noise in the receiver. Together with the presence of thermal noise, depending on the distance between the transmitter antenna and the receiving antenna, the temperature correlation with the signal level can be positive or negative. The distance contributes to the existence of this correlation since varying the distance of the station's antenna to the receiving antenna, changes the azimuth of the horizontal plane and, therefore, the intensity of the electric field. Again in the analysis of correlations between the $\mathrm{C} / \mathrm{N}$ and the light intensity accompanying the temperature in correlation with the signal level. Thus, stations F, B, and C contain linear correlation between the signal level and the light intensity significantly different from zero. The fact that stations $\mathrm{B}$ and $\mathrm{C}$ are subject to the adjacent channel effect also contributed to this similar behavior.

The wind speed was also one of the factors that influenced the reception of some stations $(\mathrm{C}, \mathrm{E}, \mathrm{F}$, and $\mathrm{G})$, interfering with the signal level. The correlation with the wind velocity was at certain stations positive and negative for others because the wind speed at certain stations promotes or hinders the transmission due to the distance from the transmitter. Similar to the $\mathrm{C} / \mathrm{N}$ ratio, humidity could possibly be influencing these results. Only for station $\mathrm{F}$ was the wind direction positively correlated with the signal level, probably due to its location. One possible factor for this relationship is the balance of the receiving antenna that changes the directivity beam of the antenna.

\section{CONCLUSION}

In this article it was concluded that digital TV is a medium that can only be studied with a view that air transmissions may be subject to various types of interference, causing changes in thousands of receivers (Set-Top Box).

It can be seen in laboratory tests completed, in which values for certain variables were applied, that the variables that occur with greater frequency in the receiver are multipath and impulse noise, and the results showed signal level loss and value in relation to $\mathrm{C} / \mathrm{N}$, when subjected to certain power levels as mentioned above.

Linear correlations were found between the meteorological variables such as temperature, speed, wind direction, and light intensity with variables representing the signal quality such as signal level and $\mathrm{C} / \mathrm{N}$ ratio for the reception of digital $\mathrm{TV}$, but these depended on location the each station's antenna in relation to the receiving antenna.

In Kruskal-Wallis non-parametric analysis, the relation of $\mathrm{C} / \mathrm{N}$ ratio and the signal level were evaluated, it was concluded that by analyzing the results and map of station transmission antennae, the distance between the station antennae and the receiving antenna influences the reception.

How much the signal function is effected by meteorological variables indicates that this study should be repeated, measurements of humidity could not be used due to failure in the measure and a possibly prolonging the period of the data evaluation.

Therefore, by applying statistical methods, it was possible to show in numbers, the factor of influence each type of 
meteorological data has on the degradation of reception quality of the digital signal.

\section{ACKNOWLEDGMENT}

The authors acknowledge the support of the Instituto Presbiteriana Mackenzie (PIBIC/Mackenzie) for this research, teachers, and friends of the laboratório da TV digital at Universidade Presbyterian Mackenzie.

\section{REFERENCES}

[1] S. Haykin, Sistemas de Comunicação Analógicos e Digitais. $4^{\text {th }}$ ed. Porto Alegre, Brazil: Bookman, 2004.

[2] D. C. Montgomery, and G. C. Runger, Estatística Aplicada e Probabilidades para Engenheiros. $4^{\text {th }}$ ed. Rio de Janeiro, Brazil: LTC, 2009.

[3] N. B. Barros, I. S. S. Scarminio, R. E. Bruns, Como Fazer Experimentos: Pesquisa e desenvolvimento na ciência e na indústria. Campinas, Brazil: Unicamp, 2003.

[4] A. W. Ramos, Melhorando o processo: delineamento de experimentos. In: R. G. Rotondaro, "Seis Sigma: estratégia gerencial para a melhoria de processos, produtos e serviços.” São Paulo, Brazil: Atlas, 2002.

[5] Receptores, NBR 15604, 2008.

[6] W. J. Conover, Practical Nonparametric Statistics. New York: John Wiley and Sons, 1999.

[7] J. Neter, W. Wasserman, M. H. Kutner, Applied Linear Statistical Models, $5^{\text {th }}$ ed. New York: McGraw-Hill, 2005.

Paulo Guedes Esperante is a graduate student in Electrical Engineering from the Escola de Engenharia da Universidada Presbiteriana Mackenzie. Scientific Initiation Scholarship PIBIC / Mackenzie to published articles.

Raquel Cymrot a BA and MA in Statistics from the Instituto de Matemática e Estatica da Universidade de São Paulo. He is currently a professor at the Escola de Engenharia da Universidada Presbiteriana Mackenzie and a member of the Research Ethics Committee - Humanos de Universidada Presbiteriana Mackenzie. He has published several articles and book chapters. He has participated in several national and international conferences.
Rodrigo Eiji Motoyama received his BS in Electrical Engineering from Universidada Presbiteriana Mackenzie (São Paulo, Brazil) in 2007. He is currently working on his Master's Degree in Electrical Engineering - Telecommunications at the Universidada Presbiteriana Mackenzie (São Paulo, Brazil). He is one of the researchers in the laboratório da TV digital at Universidade Presbyterian Mackenzie and works in both laboratory tests and field areas.

Cristiano Akamine has a Master's degree in Electrical Engineering from the Universidade Estadual de Campinas (2004) and a degree in Electrical Engineering from Universidada Presbiteriana Mackenzie (1999). He is currently a professor and researcher at the Escola de Engenharia da Universidada Presbiteriana Mackenzie. He has experience in Electrical Engineering with emphasis in Telecommunication Systems, in the following topics: digital TV, ISDB-TB systems, and DVB.

Fujio Yamada is holder of the title Professor Doctor at the Escola de Engenharia da Universidada Presbiteriana Mackenzie and a researcher at laboratório da TV digital at Universidade Presbyterian Mackenzie. He has participated in several events as a speaker and moderator at conferences and symposia presentations.

Fabio Ray graduated in Physics from Universidada Presbiteriana Mackenzie, he has a Master's degree in Computer Science from Universidada Presbiteriana Mackenzie and a Ph.D. in Reactor Technology at the Instituto de Pesquisas Energéticas e Nucleares (IPEN). He is currently a professor at Universidada Presbiteriana Mackenzie. He has published several articles in Engineering. 